\title{
Tetracyclic Condensed Pyrimidines. New Derivatives of the Benzo [4',5'] Imidazo [2',1':6,1] Pyrido [2,3-D] Pyrimidines
}

\author{
Harutyunyan $\mathrm{AA}^{1,2 *}$, Ghukasyan $\mathrm{GT}^{1}$, Safaryan $\mathrm{MS}^{1,2}$, Grigoryan $\mathrm{AS}^{2}$, and Danagulyan $\mathrm{GG}^{1,2}$ \\ ${ }^{1}$ Russian-Armenian (Slavonic) University, Republic of Armenia \\ ${ }^{2}$ Scientific Technological Center of Organic and Pharmaceutical Chemistry, Republic of Armenia
}

*Corresponding author: Harutyunyan AA, Scientific Technological Center of Organic and Pharmaceutical Chemistry (STCOPHCH), 0014, Yerevan, Azatutyan ave 26, Republic of Armenia.

To Cite This Article: Harutyunyan AA, Tetracyclic Condensed Pyrimidines. New Derivatives of the Benzo [4',5'] Imidazo [2',1':6,1] Pyrido [2,3-D] Pyrimidines. 2020 - 7(6). AJBSR.MS.ID.001201. DOI: 10.34297/AJBSR.2020.07.001201.

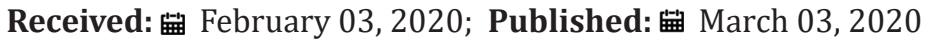

\section{Short Commentary}

The biological activity of polycyclic heteroaromatic compounds is due to their ability to interact with DNA, being associated with small and large grooves or intercalation between adjacent bases in a double helix, the interaction mechanism of the latter being considered as the main one. In both cases, the secondary structure of DNA is distorted and its functioning is disrupted, and therefore the most promising in developing new-generation drugs for the treatment of tumor diseases and viral and bacterial [1]. At the same time, many derivatives of these classes of compounds exhibit insufficient selectivity and have toxic effects on healthy cells and tissues [2]; therefore, the search for new active and more selectively acting pharmacological drugs remains an urgent task. connections with this mechanism of action are considered as the
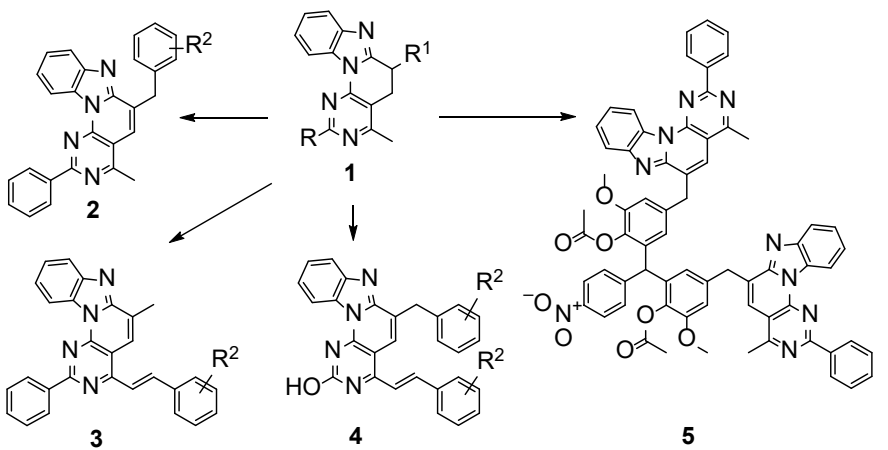

Figure 1: Benzo [4',5'] imidazo [2',1': 6,1] pyrido [2,3-d] pyrimidine.

Among the tetracyclic heteroaromatic compounds, we have drawn attention to the syntheses and biological properties of the derivatives of the heterocyclic system benzo $\left[4^{\prime}, 5^{\prime}\right]$ imidazo $\left[2^{\prime}, 1^{\prime}: 6,1\right]$ pyrido [2,3-d] pyrimidine [1], about of which there are a limited number of publications in the literature before our investigations [3-6]. Based on a fundamentally new methodology for constructing a heterocyclic system that expanded the spectrum of their reactivity $[7,8]$, it became possible to synthesize new derivatives [2-4] of the system under discussion with the involvement of meth- yl and methylene groups in the reaction and study their biological properties [9-13] (Figure 1).

In compound 5 [14] two fragments of the tetracycline are connected through a triarylmethane linker and bulky molecule has a unique three-dimensional shape, which makes it interesting in terms of potential ability for interact with various biomolecules in biomedical investigations. Antibacterial properties of some derivatives of benzo $\left[4^{\prime}, 5^{\prime}\right]$ imidazo $\left[2,1^{\prime}: 6,1\right]$ pyrido $[2,3-d]$ pyrimidines 
have been studied for strains of gram-positive bacteria (Staphylococcus aureus $209 \mathrm{p}$ and $S$. aureus 1 ) and gram-negative rods (Shigella flexneri 6858, Escherichia coli 0-55) by the methods of "diffusion in agar" and "two-fold serial dilutions", the control drug is furazolidone. It has been shown that benzo $\left[4^{\prime}, 5^{\prime}\right]$ imidazo $\left[2^{\prime}, 1^{\prime}\right.$ : 6,1] pyrido [2,3-d] pyrimidines 2-4 are completely devoid of activity, because insolubility of designed compounds [15].

The anti-monoaminoxidase properties of compounds were studied by their effect on the deamination of serotonin (5-OT) by the brain Monoamine Oxidase (MAO) in vitro, the controldrug indopan. It has been found that in contrast of antibacterial properties, tetracycles 2-4 show pronounced anti-MAO activity, inhibiting enzyme activity by $60-63 \%$ [16]. Thus, in recent years, a fundamentally new small library of previously poorly studied derivatives of benzo $\left[4^{\prime}, 5^{\prime}\right]$ imidazo [2',1': 6,1] pyrido [2,3-d] pyrimidines, including with $\pi$-conjugation extended chains, has been synthesized, and the biological activity for this class of compounds is described for the first time.

\section{References}

1. Lyakhova YA, Guseva YA, Lyahov SA, Andronati SA (2010) J Org Pharm Chem 8(2): 3.

2. Martins P, Jesus J, Santos S, Raposo LR, Rodrigues CR, et al. (2015) Heterocyclic Anticancer Compounds: Recent Advances and the Paradigm Shift towards the Use of Nanomedicine's Toolbox. Molecules 20(9): 16852-16891.

3. Dieter A (1981) Pat. 2929414, Germany CA 95: 44732.

4. Szwed KB, Czarny AJ (1993) Synthesis of polyazaheterocycles by Michael addition of $\mathrm{CH}$ acids to $\alpha, \beta$-unsaturated nitriles. Synthesis of pyrido[1,2-a] benzimidazole and pyrimido $\left[5^{\prime}, 4^{\prime}: 5,6\right]$ pyrido $[1,2-\mathrm{a}]$ benzimidazole derivatives Chem 335(3): 279-282.
5. Elwan NMJ (2004) Heterocycl Chem 41: 281.

6. El Zohry MF, Mohamed TA, Hussein EM (2009) Monatsh Chem 140: 265.

7. Harutyunyan AA (2012) Chemical Journal of Armenia 65(2): 257.

8. Harutyunyan AA (2017) Dissertation: "Studies in the field of the pyrimidines and polycyclic azaheterocycles synthesis" Doctor of chemical sciences, Yerevan pp. 247.

9. Harutyunyan AA (2014) Synthesis of tetra- and pentaaza heterocyclic systems and benzimidazo [1,2-c] quinazoline derivatives. Russ J Org Chem 50(1): 94-99.

10. Harutyunyan AA (2016) One-stage synthesis of condensed pyrimidines by reaction of substituted 3-(pyrimidin-5-yl) propanoic acids with ortho-diamines: Extension of limits. Russ J Org Chem 52(2): 235-239.

11. Harutyunyan AA, Panosyan HA, Tamazyan RA, Ayvazyan AG (2016) New production of benzo [4,5] imidazo [2', 1': 6.1] pyrido [2,3-d] pyrimidine. Chemical Journal of Armenia 69(3): 266.

12. Harutyunyan AA (2018) Synthesis and Biological Properties of Benzo [4',5'] Imidazo [2',1': 6,1] Pyrido [2,3-D] Pyrimidines: Mini-Review Chemical Journal of Armenia 71(4): 579-588.

13. Harutyunyan AA, Ghukasyan GT, Panosyan HA, Tamazyan RA, Ayvazyan AG, et al. (2019) Synthesis of New Derivatives Benzo [4',5'] imidazo $\left[2^{\prime}, 1^{\prime}: 6,1\right]$ pyrido [2,3-d] pyrimidine. Russ J Org Chem 55(11) 16981703.

14. Harutyunyan A, Panosyan H, Danagulyan G (2018) Synthesis of benzo $\left[2^{\prime}, 1^{\prime}: 6,1\right]$ pyrido [2,3-d] pyrimidine, symmetrically connected by triarymethane linker. I International Scientific Conference "Current State of Pharmacy and Prospects of its Development". Book of Abstracts. Yerevan, Armenia p. 34.

15. Harutyunyan AA, Avakimyan JA, Stepanyan HM (2016) Antibacterial properties of some polycyclic heterocycles based on pyrimidine and benzimidazole. Biological Journal of Armenia 68(2): 88.

16. Harutyunyan AA, Sukasyan RS, Grigoryan AS (2016) Inhibiting properties of some new substituted pyrimidines and condensed azaheterocycles. Biological Journal of Armenia 68(1): 60. 